\title{
A Theory of Political Control and Agency Discretion*
}

Randall L. Calvert, University of Rochester

Mathew D. McCubbins, University of California at San Diego

Barry R. Weingast, Stanford University

\begin{abstract}
A major issue in the study of American politics is the extent to which electoral discipline a]so constrains bureaucrats. In practice, executive agencies operate with considerable independence from elected officials. However, the entire process of policy execution is a game among legislators, the chief executive, and bureaucratic agents. It includes the initial delegation of authority, the choice of policy alternatives, and opportunities for oversight and control. A simple model of this process demonstrates an important distinction between bureaucratic authority and bureaucratic discretion. Indeed, in its simplest form, the model predicts a world in which bureaucrats are the sole active participants in policymaking, but in which the choice of policy is traceable entirely to the preferences of elected officials. More realistically, the model leads to a precise definition of agency discretion. These conclusions have practical applications for both students and reformers of policymaking.
\end{abstract}

Democratic constitutions attempt to constrain policymakers with the discipline of the electoral process. By mandating frequent elections, the U.S. Constitution gives representatives (in the words of The Federalist, no. 52) "an immediate dependence on, and an intimate sympathy with, the people" (Hamilton, Jay, and Madison, 1966, p. 165). Modern research has confirmed the success of this mechanism, mediated though it is by the dynamics of interest group organization (Mayhew, 1974; Fenno, 1978). Policy decisions, however, are no longer the exclusive domain of elected representatives. A major unresolved issue in the study of American politics is the extent to which the constitutional system of safeguards and incentives designed to discipline elected representatives also works to discipline bureaucrats.

According to one view, the bureaucracy operates with considerable independence from elected representatives. Legislators are unable or unwilling to perform meaningful oversight (Niskanen, 1971; Dodd and Schott, 1979, pp. 170-84; Katzmann, 1980, pp. 140-60), and the president, although perhaps effective on a few selected issues, faces severe constraints of power and resources in controlling his nominal subordinates (Neustadt, 1980; Allison, 1971, pp. 141-42, 225-26). On the other hand, a host of stud-

*An earlier version of this paper was presented at the annual meeting of the American Political Science Association, August 1986. For helpful comments on earlier versions, the authors thank David Baron, Jonathan Bendor, Keith Krehbiel, and participants in the Hoover Institution Political Economy Workshop and the Washington University Political Science Workshop. The suthors gratefully acknowledge grants from the National Science Foundation for partial support (SES-8421161 for McCubbins and SES-8717516 for Weingast).

Americen Journal of Political Science, Vol. 33, No. 3, August 1989, Pp. 588-611

- 1989 by the University of Texas Press, P.O. Box 7819, Austin, TX 78713 
ies argue that the decisions of federal agencies directly reflect the wishes of elected officials in Congress and the White House (Mayhew, 1974, pp. 10640; Arnold, 1979, pp. 207-10; Fiorina, 1981; Moe, 1985; Calvert, Moran, and Weingast, 1988). In this view, elected officials gain leverage over bureaucrats through informal oversight, using such tools as decentralized information gathering (McCubbins and Schwartz, 1984; Weingast, 1984; Aberbach, 1987) and carefully structured administrative procedures (McCubbins, 1985; McCubbins, Noll, and Weingast, 1987) to guarantee that the relevant legislative constituents are well served.

We address this unresolved issue with a simple model of the policy process. Implicit in the structure of decision making created by the Constitution is a game that pits the ambitions of institutional actors against one another. In particular, the process of policy execution is a game among legislators, the chief executive, and bureaucratic agents; it includes the initial delegation of authority, the choice of policy alternatives, and opportunities for oversight and control. The actions of political officials throughout this process jointly determine policy outcomes. Our aim is to examine the sequence of decisions made by elected representatives and bureaucrats, to explore the strategies available to them, and to assess the policy outcomes that result.

As our analysis demonstrates, the fact that bureaucratic agents appear to make policy with little direct input from elected officials does not necessarily imply that bureaucrats are responsible for policy choices or that they employ meaningful "discretion." Bureaucratic choice is embedded in a game in which the appointment power of the executive and legislature, together with the threat of sanctions, provides a potentially decisive infiuence over policy. In its simple form, this game's equilibrium has two important properties. First, bureaucrats are the sole active participants in policymaking. Second, however, the actual choice of policy is traceable not to bureaucratic preferences but to the preferences of legislative and executive politicians.

This approach also leads us to a precise definition of agency discretion. The simple game whose outcome we have just described is relevant when politicians possess sufficient information about the preferences and beliefs of appointees, or sufficient willingness to oversee agency decision making. When the information is poor and the willingness is lacking, there is room for agency discretion. Discretion consists of the departure of agency decisions from the positions agreed upon by the executive and legislature at the time of delegation and appointment. Thus even though the agency may be the sole active decision maker, policy outcomes are traceable to the preferences of all three institutions and to the constitutional process in which they act.

A further implication of this approach is the following comparative statics result: all else equal, the more important a policy area to politicians, the 
lower the amount of agency discretion. This follows because in those areas in which they care the most, politicians will expend greater effort and resources in reducing the uncertainty that affords bureaucrats the opportunity for discretion.

Beyond these theoretical issues in democratic politics, our study has two important practical applications. First, any attempt to improve policy outcomes systematically through structural or procedural reform depends on a sophisticated understanding of where the relevant policy decisions are made. If, for example, the legislature is primarily responsible for the content of policy outcomes, then no amount of reform of the bureaucratic process is going to make much difference, and "improvements" in the oversight capabilities of the legislature will just enhance existing tendencies.

Second, empirical analysis of the policymaking process, particularly using the case study approach, can be seriously misdirected if the analyst does not have the proper understanding of the nature of responsibility for policy outcomes. In studying policymaking it is natural to focus on the units making the actual decisions. However, concentrating on acts of decision making rather than on influences over decision making is a kind of myopia that can lead to false conclusions about where the responsibility for policies lies. ${ }^{1}$

We proceed as follows. The first section presents a stylized model of the process of policymaking. It includes an intial stage wherein elected officials choose an appointee; a choice stage in which the appointee, as bureaucratic agent, determines a policy choice; and a final stage in which the legislature and executive react to the decisions of the agent. Using this simple model, we exhibit the nature of equilibrium behavior by all the participants in the process and analyze their contributions to the policy choice. The second section relaxes the basic model's assumption of perfect information to get a useful characterization of agency discretion. The third section explores some variants on the legislative and executive powers in the basic model in order to underscore the generality of the basic model's conclusions. The final section offers prescriptions and cautions for empirical analysts of the process.

\section{A Simple Model of the Policy Process}

The model in this section focuses on the essential features of the policymaking process in order to draw conclusions about how its outcomes are determined. Although the real world is considerably more complicated than, and in some respects just plain different from, the basic model, many of the same general conclusions ought to hold. In particular, well-chosen agents, in an agency constructed to channel their incentives correctly, can

\footnotetext{
${ }^{1}$ Some examples of the ambiguities of such an approach are explored in Calvert, Moran,
} and Weingast (1988). 
potential agents having ideal points everywhere in the relevant policy space. Suppose that each actor has strictly convex preferences over the entire policy space. Given the perfect-information environment of our simple model, we lose no generality by assuming from the outset that $x_{a}$, as well as the ultimate policy choice of the agent, will lie on the contract curve of the legislature and executive, that is, on the locus of tangency points of their indifference curves. Thus we may as well assume that the relevant policy space is the real line, $\mathbf{R}$, with $x_{\ell}=0$ and $x_{\ell}=1 .{ }^{3}$ The legislature and executive are to determine, in a manner to be described below, a value for $x_{a}$; then an agent is to choose a policy $x$. This choice is then subject to veto by either the executive or the legislature.

Now let us simplify further by assuming that the actors' utility functions on this unidimensional policy space take the following form: for the agent,

$$
u_{a}(x)=v_{a}-\left|x-x_{a}\right|
$$

for the executive,

$$
u_{e}(x)=v_{e}-|1-x| ;
$$

and for the legislature,

$$
u_{\ell}(x)=v_{k}-|x| .
$$

If no agent is agreed upon by the legislature and executive, or if the agent's choice is vetoed by either elected official, then all three players receive a payoff of zero. The higher the values of $v_{a}, v_{e}$ and $v_{\ell}$, the greater departure from the ideal that each actor is willing to accept in order to get some agency decision implemented rather than none.

The stages in our game are as follows; each stage is justified and analyzed below. First, the legislature and executive determine the agent's preferences in a Nash bargaining process (Nash, 1950). The threat point for this process is the "no decision" outcome. Second, the chosen agent picks a policy $x$. Third, the legislature and executive decide simultaneously whether to exercise their veto powers. Then the players receive their payoffs, and the game ends. For reasons that will be apparent, we take up these stages in reverse order.

\section{The Veto Stage}

The veto stage represents the ability of a real world legislature or executive to prevent an agency's decision from taking effect, but only at the

3hatever the bargaining process, there is no reason for the executive and legislature to settle on an agent ideal point off their contract curve, since they could both be made better off by locating at some point on the contract curve. Likewise, they should never agree on a point on the curve but beyond the segment between their ideal points. 
be left alone to determine the policy that the elected officials would themselves have chosen, given the time and resources. Failing this, the possibility of retribution or circumvention after the fact may still limit the extent to which an agent is willing to exercise the discretion available.

The general structure of our basic model is as follows. We assume that two elected officials (a legislature and an executive) share the power to appoint an agent. The agent will then choose a policy alternative. These three actors have different preferences about what the policy should be; however, the legislature and executive can choose their agent's preferences by choosing a mutually agreeable individual from a pool of available candidates. Initially, we assume that the actors have complete information about all aspects of the process, so that the elected officials know exactly what they are getting when they make the appointment. For simplicity, we treat all three actors as individual decision makers in order to focus our analysis on the basic process. ${ }^{2}$

In addition to their preferences over policy outcomes, all three actors attach some independent value to reaching some policy decision as opposed to deadlock. After the agent chooses a policy, both the legislature and the executive have the power unilaterally to void that decision through some sort of veto. In that case the outcome is equivalent to a deadlock over the original appointment.

In this section we first set up and solve the basic model. We then examine its properties and describe the roles of the players in determining policy. Then in the next section we shall turn to the effect of adding uncertainty to the basic model.

\section{The Basic Model}

Let $x_{f}$ be the ideal point of the legislature in a set of policy alternatives that is a convex subset of some (multidimensional) Euclidean space. Let $x_{e}$ be the ideal of the executive, and $x_{a}$ that of the chosen agent. Throughout the paper we assume that the nominations are drawn from a large pool of

'This approach assumes away two potentially important aspects of the policy process. First, there are problems of organizational monitoring and compliance as the appointed agent attempts to control the bureaucracy. The effect of adding this feature to the model is akin to the effect of adding monitoring problems to the veto stage of the basic model, as discussed below in the text. Second, there are problems of the instability of social choice within the organizations that, in the real world, make up all three of our "players." Hill (1985) and Hammond, Hill, and Miller (1986) point out that, in principle, the agent could take advantage of majority rule cycles within the legislature to avoid any legislative control. The same reasoning might be applied in reverse: social choice in a bureaucratic organization is in theory no better behaved than in the legislature. We suspect that such problems are overcome through structural constraints and repeated interaction within each type of organization, and so we ate willing to ignore them for the time being. 
potential agents having ideal points everywhere in the relevant policy space. Suppose that each actor has strictly convex preferences over the entire policy space. Given the perfect-information environment of our simple model, we lose no generality by assuming from the outset that $x_{a}$, as well as the ultimate policy choice of the agent, will lie on the contract curve of the legislature and executive, that is, on the locus of tangency points of their indifference curves. Thus we may as well assume that the relevant policy space is the real line, $\mathbf{R}$, with $x_{t}=0$ and $x_{e}=1 .^{3}$ The legislature and executive are to determine, in a manner to be described below, a value for $x_{a}$; then an agent is to choose a policy $x$. This choice is then subject to veto by either the executive or the legislature.

Now let us simplify further by assuming that the actors' utility functions on this unidimensional policy space take the following form: for the agent,

$$
u_{a}(x)=v_{a}-\left|x-x_{a}\right|
$$

for the executive,

$$
u_{e}(x)=v_{e}-|1-x|
$$

and for the legislature,

$$
u_{\xi}(x)=v_{\xi}-|x| \text {. }
$$

If no agent is agreed upon by the legislature and executive, or if the agent's choice is vetoed by either elected official, then all three players receive a payoff of zero. The higher the values of $v_{a}, v_{e}$, and $v_{k}$, the greater departure from the ideal that each actor is willing to accept in order to get some agency decision implemented rather than none.

The stages in our game are as follows; each stage is justified and analyzed below. First, the legislature and executive determine the agent's preferences in a Nash bargaining process $(\mathrm{Nash}, 1950)$. The threat point for this process is the "no decision" outcome. Second, the chosen agent picks a policy $x$. Third, the legislature and executive decide simultaneously whether to exercise their veto powers. Then the players receive their payoffs, and the game ends. For reasons that will be apparent, we take up these stages in reverse order.

\section{The Veto Stage}

The veto stage represents the ability of a real world legislature or executive to prevent an agency's decision from taking effect, but only at the

${ }^{3}$ Whatever the bargaining process, there is no reason for the exccutive and legislature to settie on an agent ideal point off their contract curve, since they could both be made better off by boating at some point on the contract curve. Likewise, they should never agree on a point on the curve but beyond the segment between their ideal points. 
cost of delaying any action or of having to spend time and resources to make the decision without an agency's assistance. Such powers may take various forms, such as a genuine veto, budgetary retaliation, direct legislative action to make policy, or firing of an agency head by the executive. In section 3 we examine more closely some alternative models of this veto power, but we can make our point here while keeping it simple.

Since there is no independent cost to exercising the veto, we can examine the legislature's and executive's decisions separately. The executive should veto if the outcome $x$ is worse than "no decision," that is, if $u_{e}(x)<0$. For $x$ in the unit interval, this means the executive vetoes if $x<1-v_{e}$. Likewise, the legislature vetoes if $u_{f}(x)<0$, or for $x$ in $[0,1], x>v_{\ell}$.

\section{The Policy Decision Stage}

We now back up to the choice to be made by the agent. If 1 $v_{e}>v_{t}$, then the agent cannot possibly please both masters, and veto is inevitable. Otherwise, if the agent is to avoid being vetoed, it must choose $x$ from the interval [ $\left.1-v_{e}, v_{f}\right]$. If the distance from $x_{a}$ to this interval is more than $v_{a}$, then the agent prefers to be vetoed anyway, and we may as well assume that the agent's choice is $x=x_{a}$. On the other hand, if $x_{a}$ is in the interval $\left[1-v_{e}-v_{a}, v_{\ell}+v_{a}\right]$, then the agent wishes to avoid the veto. If $x_{a}$ is actually in $\left[1-v_{e}, v_{\ell}\right]$, the agent simply chooses $x=x_{a}$. Otherwise, the agent chooses the nearest point to $x_{a}$ that will not be vetoed. To summarize,

$$
\begin{array}{cl}
x=x_{a} \text { (vetoed) } & \text { if } x_{a}<1-v_{e}-v_{a} ; \\
1-v_{e} & \text { if } 1-v_{e}-v_{a} \leqslant x_{a}<1-v_{e} ; \\
x_{a} & \text { if } 1-v_{e} \leqslant x_{a} \leqslant v_{e} ; \\
v_{\ell} & \text { if } v_{\varepsilon}<x_{a} \leqslant v_{\ell}+v_{a} ; \text { and } \\
x_{a} \text { (vetoed) } & \text { if } v_{\xi}+v_{a}<x_{a} .
\end{array}
$$

These choices are illustrated in Figure 1.4

\section{The Appointment Stage}

Finally, we arrive at the first stage of the game, in which the legislature and executive engage in a Nash bargaining game over the type of agent to appoint. ${ }^{5}$ Their payoffs from appointing an agent with ideal point $x_{a}$ are the payoffs they would receive from the policy process given the optimal behavior of an agent with that ideal point in the policy decision stage, and given their own subsequent optimal behavior in the veto stage. The "threat point," the payoff from failing to reach any agreement on the appointment,

"We have modeled this as a one-shot affair, but similar results can be obtained from a repeated-game version. See Appendix A.

${ }^{5}$ For a justification of this approach, see Appendix B. 


\section{FIGURE 1}

Policy Choice, $x$, as a Function of Agent's Ideal Point, $x_{*}$

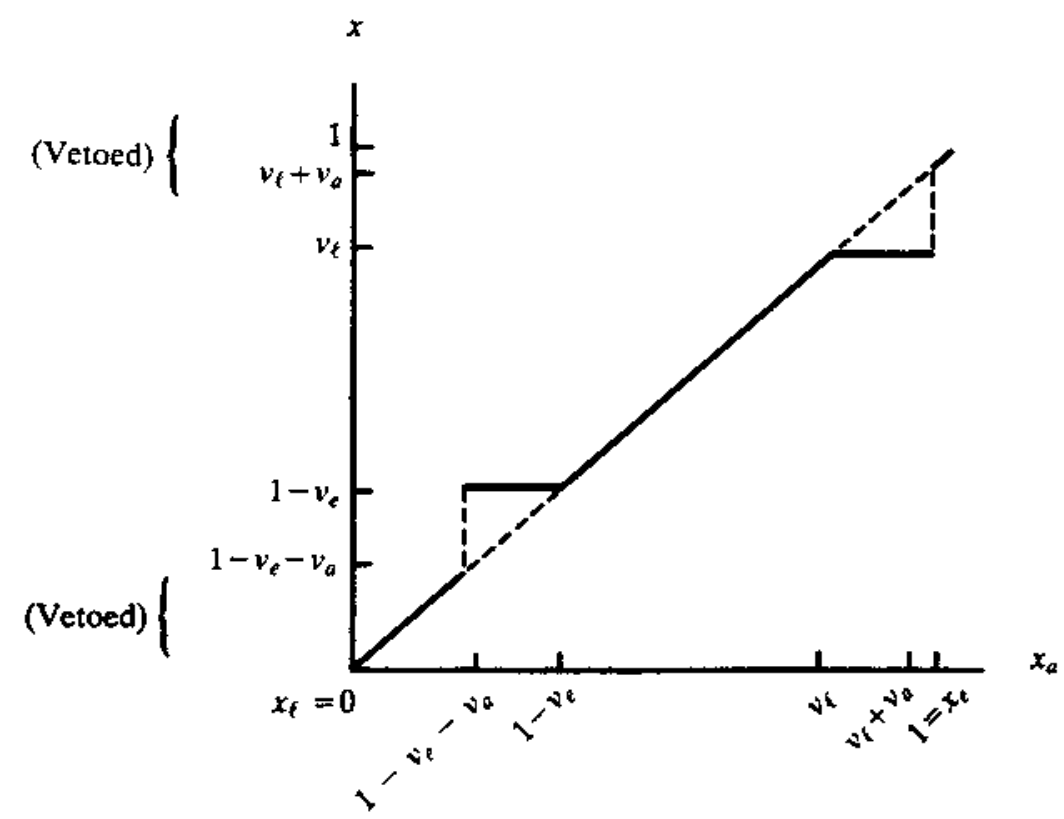

Note: (In this diagram, it is assumed that $0<v_{e}<1,0<v_{\epsilon}<1, v_{q}<1-v_{e}$, and $\left.v_{a}<1-v_{t}\right)$

is zero for each player. The "negotiation set," that is, the set of agent ideal points that are Pareto optimal for the legislature and executive and make both of them better off than the threat point, is the interval [ $\max \{0,1-$ $\left.\left.v_{e}\right\}, \min \left\{1, v_{k}\right\}\right]$. Of course, if $1-v_{e}>v_{k}$, then no mutually profitable agreement is possible.

The Nash bargaining solution (NBS) requires that the product of the two players' utility gain over their threat point be maximized. Thus the NBS occurs when the executive nominates, and the legislature accepts, an agent with ideal point $x_{e}^{*}$, the value of $x_{a}$ that maximizes $\left(v_{e}-\left|x_{g}\right|\right)\left(v_{e}-\left|1-x_{a}\right|\right)$ over all values of $x_{a}$ in the negotiation set. Thus $x_{a}^{*}=\left(v_{\varepsilon}+1-v_{e}\right) / 2$ provided that this value lies in the unit interval; if the value is less than 0 , set $x_{o}^{*}=0$; if it is greater than 1 , set $x_{a}^{*}=1$. 


\section{The Roles of the Players in Determining Policy}

Under the assumptions of the basic model, then, we can predict the ultimate policy decision, given the preferences of the executive and the legislature. Since $x_{e}^{*}$ is in the interval $\left[1-v_{e}, v_{k}\right]$, the appointed agent will have ideal point $x_{a}=x_{a}^{*}$ and will choose $x=x_{a}^{*}$ as the policy; it will not be vetoed. Thus the ultimate policy decision is determined by $x=\left(v_{\ell}+1-\right.$ $v_{e} / 2$. In the basic model, although policy decisions are made by an agent, they are really determined by the preferences of the elected officials.

In a comparative staties sense, any shift in $v_{e}$ or $v_{\ell}$ has a straightforward effect on $x$ : for a unit increase in $v_{\ell}$ or a unit decrease in $v_{e}$, there will be a $1 / 2$-unit increase in the final location of $x$. More generally, in a multidimensional policy space, any shift in the executive's or legislature's ideal point means a corresponding shift in the location of their contract curve, and thus in the appointed agent's ideal and the policy outcome.

Thus in the basic model, the legislature and executive have complete control over the policy outcome through their bargaining process in appointing the agent. Active monitoring and control of the agency's decisions plays no role. Of course, there is more to the real world process of policymaking than this; in particular, the players' uncertainty at every stage of the process is a key feature, to which we turn in the next section. But in all our subsequent development of the model, the appointment stage remains as the initial control over agency decisions, and policy outcomes continue to reflect the bargain struck between the two elective branches of government.

\section{Uncertainty and Agency Discretion}

The conclusions of the basic model result directly from the assumption that the executive and legislature have perfect information. Imperfect information could arise at many points in the process. The elected authorities might not know exactly the true preferences of the agent. Indeed, policymaking by an agency often starts with the gathering of information about the policy problem to be addressed, information presumably not known to the elected authorities at the time of the appointment. It may not even be clear in advance what the ultimate policy alternatives will be. In a broader conception of the model, an agent may face a stream of policy problems over time, among which only the earliest, if any, can be accurately anticipated by the appointing players. Any slippage between the expectations of the appointers and the preferences of the appointee creates the possibility that the agent's preferences will have an independent effect on the ultimate policy choice.

In this section we examine some of these sources of uncertainty in the context of the basic model developed in section 1 . The model becomes in- 
tractable when uncertainty is included, but we can interrogate the basic model to learn the effects of uncertainty on policy choice. In doing so, more detail emerges concerning the sources of policy choice. In particular, we are able to give a formal definition of agency discretion and distinguish it from agency choice.

\section{Uncertainty about Agent Preferences}

Suppose that, for any of the reasons cited above, the executive and legislature are unable to observe the true ideal point $x_{a}$ of any potential agent $a$. Instead, the true $x_{a}$ consists of the elected officials' intended or expected value, $x_{a}^{*}$, plus some (apparently random) deviation $\delta$ whose expected value is zero. Here, we return to the multidimensional formulation of the model, so both $x_{a}^{*}$ and $\delta$ are vectors in $\mathbf{R}^{n}$.

Suppose momentarily that the possible values of $\delta$ are restricted so that, with probability 1 , the true $x_{a}$ lies between the executive's and legislature's ideal points and would not be vetoed by either elected official if it were chosen by the agent as the final policy. Then, using the same reasoning as in section 1, the agent would make that choice. Given the linear utility functions we assumed earlier, both the executive and legislature thus have, in the appointment stage,

$$
E u_{i}\left(x \mid x_{a}^{*}\right)=E u_{j}\left(x_{a}^{*}+\delta\right)=E u_{i}\left(x_{a}^{*}\right)=u_{i}\left(x_{a}^{*}\right) .
$$

Thus the Nash bargaining process would have the same outcome as before. The difference would appear only at the policy choice stage, when the agent's true preference is revealed.

Unfortunately, this simplifying assumption, the restriction of $\delta$, is not very appealing. The restriction depends on the values $v_{e}$ and $v_{\ell}$, so comparative statics on those two parameters are not possible without further restrictive assumptions. If instead we let $\delta$ range freely, the bargaining outcome may be affected. ${ }^{6}$ The bargaining model becomes intractable, and we cannot derive an easy formula for comparative statics as in the basic model. Fortunately, however, we can still learn much about the process simply by examining the effect of deviations, $\delta$, from the expected policy in the basic model.

\section{Effects of Uncertainty}

We return now to the basic model, but ignore the particular derivation of $x_{a}^{*}$, and add the assumption that $x_{a}=x_{a}^{*}+\delta$. Within the interval

The reason for this is as follows. There is a positive probability that the true $x_{\text {a }}$ would be outside the no-veto region, in which case the agent would either choose $x \neq x_{a}$ to avoid the veto, or choose $x=x_{0}$ and be vetoed, resulting in a payoff of zero to all players. Either way, $x$ is no longer a linear function of $x_{j}^{*}$, so $E u_{f}\left(x \mid x_{j}^{*}\right) * E u_{i}\left(x_{j}^{*}\right)$ and the expected payoff from appointing an agent with expected ideal $x_{A}^{*}$ is different from the payoff of doing so under certainty. 
[1 $\left.-v_{e}, v_{t}\right]$, where no decision is vetoed, every change in $x_{q}$ means a corresponding change in the ultimate policy choice $x$. This interval is the area of agency discretion. Just outside the interval, but within $v_{a}$ of its endpoints, small changes in $x_{a}$ make no difference, as the agent chooses the nearest endpoint to avoid a veto. This is the area of latent political control. Further than that from the no-veto interval, the agent would rather be vetoed than implement a repugnant policy, and the result is just that. This is the area of active political control. Finally, changes in $v_{a}$ alter the range in which latent control occurs, and changes in $v_{e}$ and $v_{t}$ alter all three areas. Of course, in our original, multidimensional policy space formulation, it would also be possible for $x_{a}$ to lie off the contract curve of the executive and legislature. A similar analysis applies in that case. The area for agency discretion would be narrowed the further $x_{a}$ lies off the contract curve. The general case is illustrated in Figure 2.

\section{FIGURE 2}

Areas of Agency Discretion, Latent Political Control, and Active Political Control as a Function of $x_{a}$ in the Multidimensional Model

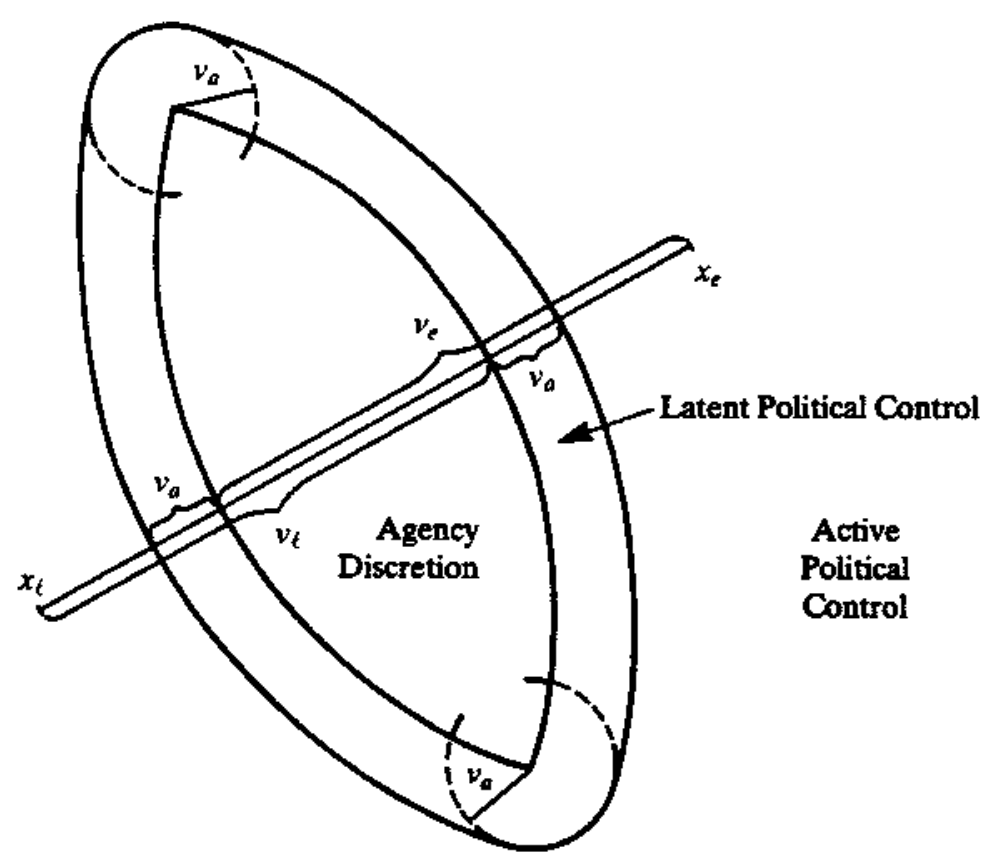




\section{Agency Discretion and the Sources of Policy}

This simple analysis offers some conclusions about who is responsible for policy outcomes. Suppose that $x_{a}$ is in the no-veto interval; then the policy outcome is $x=x_{a}$. Certainly this differs from both the legislature's and the executive's ideals; for at least one of them, it is worse than $x_{a}^{*}$. Suppose for example that $\delta>0$. The observer of the policy process would see the agent make a decision consistent with agent preferences, while the legislator complains about the difference between $x$ and $x_{\boldsymbol{f}}$. Even the executive (who probably does not complain) realizes a policy choice that differs from $x_{e}$. Is it reasonable, then, to conclude that the agent is "responsible for" or "controls" policy, or that the elected officials have been disfranchised? As our model makes clear, the answer is no: agency discretion only allowed the agent to implement the difference $\delta$, while the base from which the agent departed, $x_{a}$, was chosen by the elected officials. If the legislature or executive had had different preferences, the policy outcome would have been different.

If $x_{a}$ lies outside but near the no-veto interval, appearances can be even more deceiving. The agent unilaterally chooses a policy different from that expected by the executive and legislature, and as different from one of them as the agent can possibly get away with. That choice is tempered, however, not only by the original $x_{a}^{*}$ intended by the appointment, but also by the agent's anticipation of a utility-reducing veto if $x=x_{a}$ were chosen. Here again, although the agency makes the actual decision, and decides partly in line with its own preferences, the policy outcome is attributable in part to political control. This control is prospective, exercised through the appointment process and through latent oversight. Only if the agent's ideal lies far from the no-veto interval does the observer of the policy choice see any active political control; the result is undesired delay and unanticipated extra work for the executive and legislature. The better the information in the hands of the elected officials, the rarer the latter outcome will be.

In any of the cases in which the agency is not vetoed, we can define agency discretion as a component of the chosen policy. The most important point of this model is that agency discretion does not consist of the difference between the agency's choice and the legislature's wishes, or between the agency's choice and the executive's wishes. Much less does it lie in the fact that the agency makes the actual policy choice, or that the elected officials exercise no active oversight of the choice. Rather, agency discretion is the difference, $x-x_{a}^{*}$, between the agency's choice and the choice the elected officials thought they were getting when they agreed on a nominee. Any other difference from either elected official's wishes is attributable to the ap- 
pointment process, not to the agency. To put this another way, the appointment process is a component of the agency's final decision. It is, just as in the basic model, the initial tool of the elected officials in determining policy.

Thus the structure of the policy game establishes incentives and constraints that discipline bureaucratic choice. The agent's goals are predetermined, subject to error, by elected officials. Anticipation by the agent of legislative or executive reaction is sometimes sufficient to bring its policy choices further into line with the elected official's original expectations. If the error in the appointment stage is not too large, then, direct or active intervention by those officials would be redundant. As a result of these factors, a process that seems on the surface to exhibit wide agency discretion can conceal even heavy influence by elected officials. The bureaucracy is subject, indirectly, to the discipline of elections.

\section{Uncertainty about Agency Choices: The Monitoring Problem}

Uncertainty at the veto stage of our policy process can also give rise to agency discretion. Suppose that the potential vetoer of the agency's choice does not know with certainty the precise location of that choice. This is the standard monitoring problem from agency theory. Such uncertainty could in principle arise either from lack of information about the details of agency actions or lack of understanding about the implications of agency actions for ultimate policy outcomes. This might make it possible for the agency to conceal the true implications of its choices from the elected officials at least for a time. Agency discretion would then consist of the departure of the true policy $x$ from the appointed $x_{a}^{*}$ and would be limited by the possibility of a veto based on an estimated policy $x^{\prime}$ derived from any partial information about agency actions.

The monitoring problem occurs only when the agency has information not possessed by any politically relevant actor displeased by the agency's choice. If the preferences of elected officials are derived from the interests of constituents, and if agency decisions are a matter of public record, then such a pattem of expertise and preferences should be rare. In the U.S. context, for example, organized interest groups typically do have the relevant technical information; as a last resort, if adversely affected by an agency choice, such groups can inform elected officials and encourage them to take remedial action (McCubbins and Schwartz, 1984). Further, administrative procedures are typically designed to force maximum revelation of the information and actions of an agency (McCubbins, Noll, and Weingast, 1987). Thus agency discretion in the federal government does not often result simply from ignorance on the part of elected officials, unless the political stakes of the agency's policies are low. 


\section{Other Executive and Legislative Powers}

Our model portrays the legislature as having a simple ex post veto power over agency decisions. More commonly, real world legislatures wield less direct controls over agency actions. Most important of these are the legislature's control over program authorizations and appropriations that enable the agency to make policy at all. Likewise, the executive usually wields powers other than a simple veto of the agency's decision, ranging from the ability to fire the agent unilaterally to the responsibility for compiling budget requests.

In this section we examine brieffy some alternative versions of the basic model in which, instead of an ex post veto, the elected authorities wield more realistic powers over the agency. The main point of this section is that, in their general shape, the results are not significantly different from those of the basic model. However, we will be able to sketch some of the marginal dependencies of policy outcomes upon the powers accorded to political officials. The powers modeled here include: legislative budget authority; overriding agency decisions through direct legislation; executive firing; and "independent agencies."

\section{The Power of the Purse}

Suppose now that the legislature, instead of wielding a veto, makes a budget decision after learning the agency's intended policy. Let $b$ be the budget allocated to the agency by the legislature. It is reasonable to suppose that the extent to which the agency is funded will determine the effectiveness of the agency's policy; given our previous normalization of utility so that "no action" carries a utility of zero for each player, the impact of budget size on payoffs can be formalized as follows:

$$
\begin{array}{ll}
\text { Agent: } & u_{a}(x, b)=b\left[v_{e}-\left|x-x_{a}\right|\right] \\
\text { Executive: } & u_{e}(x, b)=b\left[v_{e}-|1-x|\right] \\
\text { Legislature: } & u_{\ell}(x, b)=b\left[v_{\ell}-|x|\right] .
\end{array}
$$

In this setting, the legislature will choose $b=0$ if the bracketed term in the definition of $u_{\ell}$ is negative and will make $b$ as large as possible if the bracketed term is positive. The funds that the legislature is willing to contribute to the agency are limited by the opportunity costs of not spending that money on other valued activities. So let us modify the legislature's utility function as follows:

$$
\text { Legislature: } u_{\ell}(x, b)=b\left[v_{\ell}-|x|\right]-c(b),
$$

where $c$ is an increasing, convex function with $c(0)=0$. Now, if the bracketed term is positive, the utility-maximizing budget for the legislature sets 


$$
v_{\ell}-|x|=c^{\prime}(b)
$$

which occurs at a unique, positive value of $b$. Call this value $b(x)$. For example, if $c(b)=b^{2}$, then $b(x)=\left(v_{\ell}-|x|\right) / 2$.

In this new version of the game, the executive's veto decision is made exactly as before. However, the upper limit imposed on the agent's decision by the possible legislative veto is now replaced by a budgetary incentive for the agent. To see this we first demonstrate that the legislature always provides a lower budget for less preferred (i.e., higher) values of $\boldsymbol{x}$. Differentiating the first-order condition for the legislature's maximization problem gives

$$
\frac{d}{d x}\left(v_{\ell}-|x|-c^{\prime}(b)\right)=0
$$

If the agent chooses $x \geqslant 0$ (which makes all three players better off unless $x_{e}<0$ ), this gives

$$
-1=\frac{d}{d x} c^{\prime}\{b\}=\frac{d}{d b} c^{\prime}(b) \frac{d b}{d x}
$$

so

$$
\frac{d b}{d x}=\frac{-1}{c^{n}(b)}
$$

which is negative by convexity of $c$ assumed above. Thus the agent, in choosing $x$, must trade off the desirability of being close to $x_{a}$ against the desirability of a higher budget and will choose $x$ somewhere between $x_{e}$ and the legislature's ideal point, 0 . Denote the resulting policy choice by $x=$ $\xi\left(x_{a}\right)$.

All these incentives should be anticipated in the appointment stage by both the executive and legislature. The outcome of that bargaining problem will again be the value of $x_{a}$ that maximizes the product

$$
u_{e}\left[\xi\left(x_{a}\right), b\left(\xi\left(x_{a}\right)\right)\right] \cdot u_{d}\left[\xi\left(x_{a}\right), b\left(\xi\left(x_{a}\right)\right)\right] .
$$

The outcome will differ from that in the basic model due to the inclusion of the opportunity cost term $c(b)$ in $u_{\ell}$ and to the shift induced in $\xi\left(x_{a}\right)$ by budgetary considerations.

An alternative sequence of events is to have the legislative budget decision made before the agency reveals its policy choice. This takes account of the fact that the legislature may have to commit funds before the agency actually takes any action. Again, the difference with the basic model's outcome would be minimal. The legislature would anticipate the agency's ultimate choice in determining $b$ as well as in the appointment stage. Thus $b$ 
would no longer depend on a particular value of $x$ (once $x_{a}$ is established), and the agency would no longer have to adjust $\xi\left(x_{a}\right)$ to improve its budget, so we have $x=x_{a}$ once again. In this formulation the legislature has no ex post sanctions to apply at all.

This "power of the purse" model makes two main points. First, when we give the legislature a continuous, ex post sanction, such as the amount of money to appropriate for the agency, the agency has an incentive to shade its policy choice toward the legislature's ideal point to take advantage of that inducement. ${ }^{7}$ Similarly, we could imagine the executive having some sort of continuous tool, particularly in a repeated game version of the model, in which the executive might grant or withhold future political cooperation with the agent to varying degrees. This alters our interpretation of political control somewhat. Here the legislature is engaged in active, rather than latent, control over the entire range of agency choice because the budgetary decision is made contingent on the agency's policy choice.

Second, aside from this matter of interpretation, the model differs little qualitatively in its outcomes from the basic model. In both, the executive and legislature bargain over the choice of an agent, attempting to choose one whose preferences will lead to a policy mutually agreeable to them. In both, the agent makes the actual choice, influenced (perhaps subtly) by the threat or actuality of executive and legislative responses. In both, true agency discretion consists of the agent's ability and desire to depart from the policy expected by the elected authorities.

\section{Executive Firing and Independent Agencies}

Some "real world" oversight powers would function in the model precisely like veto power in our basic model. Suppose, for example, that the executive has the power to fire the agent unilaterally in the final stage of the game. This works exactly like the veto power; now, we interpret $v_{a}$ to be the value the agent attaches to staying in office, independent of the policy choice.

Suppose that the executive possesses such power, while the legislature has no ex post threat at all. Now the agent ignores the basic model's legislative veto constraint, that $x \leqslant v_{\ell}$. Under the assumption of perfect information, of course, this leaves the final outcome unaffected: the legislature's threat point in the appointment bargaining game is still to hold the executive to a payoff of zero, which can be accomplished by simply refusing to approve any appointments. Thus $x_{a}^{*}$ is the same as before. If there can be any mistake about $x_{a}$, however, the legislature must worry more about the consequences,

\footnotetext{
${ }^{7}$ While this is an advantage to the legislature in the policy choice stage, the executive will take it into account earlier, in the appointment stage, demanding a closer agent ideal point.
} 
since the seriousness of a mistake is no longer.limited by the legislature's ability to zero out the payoffs after the fact. In this case there is no political control, latent or active, exercised by the legislature.

The opposite model obtains in the case of an independent agency such as those in the U.S. government. The legislature retains budgetary and authorization control over such an agency, but the executive has, in theory, no recourse once the appointment is made. Again, the possibility of an error in the appointment stage is now somewhat more worrisome to the executive. But as long as the appointment results in $x_{a} \in\left[1-v_{e}, v_{\ell}\right]$, the outcome will still be exactly as in the basic model. In these one-sided control models, the elected official without ex post controls can compensate for that weakness through the appointment process.

\section{Direct Legislation}

Any power delegated to an agency can always be taken back again. If some policy is desired, the alternative to leaving the agency's decision in place is for the legislature to legislate directly, subject to executive approval. In the terms of the basic model, we could replace the veto power with the ability of the legislature and executive to override the agency's decision through direct legislation. Then the terms $v_{e}$ and $v_{\ell}$ become the utility attached by those two players to having the agency make the decision for them, rather than having to do it themselves, possibly with some delay or likelihood of deadlock.

If this is the only way that the elected authorities can alter an agency decision, it will be invoked only if $x$ lies outside the contract curve between the executive and legislature. Otherwise, one of them is sure to be made worse off by the result. If $v_{a}>1$ or $v_{\ell}>1$, the bounds may be even wider, since some agency actions will not be worth correcting.

The result of direct legislation should be very much like the process of appointment. Now, only the legislature can propose laws, while the executive can sign or veto them. But again (as in Appendix B), the repeated interaction between the executive and legislature should prevent the legislature from baving all the bargaining power, just as it prevents the executive from having it in the appointment process. Again the NBS provides a reasonable guess about the outcome. Hence, the result of direct legislation should be precisely $x_{a}^{*}$-just what the elected authorities intended in the first place. If the payoffs from direct legislation, $u_{e}\left(x_{a}\right)$ and $u_{\ell}\left(x_{a}\right)$, are incorporated into the $v_{e}$ and $v_{\ell}$ terms, the result is similar to that of the basic model.

\section{Alternative Powers of Political Control}

After-the-fact controls over agency action in real governments are some complicated combination of the alternatives modeled here. A more realistic 
model incorporating them all would be difficult to work with; yet from the results presented here, it is clear that the general outline of our conclusions from the simple model in the first section remain in force. Through the appointment process, the elected authorities play a critical role in determining the ultimate policy outcome, more so if their guesses about the appointee's true preferences are fairly accurate. The threat of ex post action by the elected authorities provides a measure of latent control over the agent's actions. The most active oversight and control will be reserved for those instances, rare under conditions of fairly extensive information and more common when uncertainty is high, when the agency most surprises its political masters.

Finally, the executive and the legislature may have different abilities to affect agency decision making after the delegation and appointment. Our analysis indicates that when members of one branch know that their abilities to discipline agencies after the fact are weaker than the abilities of the other branch, they will insist on appointments and procedural features before the fact that tend to compensate for these differences.

\section{Discussion}

The issue of political control of bureaucratic decision making has spawned a large literature focusing on the question of whether the electoral constraints faced by politicians extend to the decisions made by bureaucrats. Our model addresses this issue by separating the influences of elected representatives and bureaucratic decision makers and identifying their distinct contributions toward policy outcomes. The various modifications of our basic model indicate that, although stylized, the model captures the essence of the game that would hold as well in more complex, specialized, and realistic models.

The most important result of our analysis is its demonstration of the role of the appointment process in influencing ultimate policy choices. In applying our model, the "appointment" stage should be taken to include any actions that the executive or legislature can take, prior to agency choice, that influence the later goals of the agent or the set of feasible choices available to the agency. Such actions include the structuring of the agency itself, the denomination of its powers and jurisdiction, the specification of administrative procedures to be followed, and the type of personnel with which the agency is to be staffed (lawyers, economists, engineers, generic civil servants, etc.).

In principle, it does not take a formal analysis such as ours to argue the significance of the appointment stage; however, it is useful to compare the role of the appointment with the roles of agency choice and executive and legislative sanctions in a model that includes all those elements together. Our model emphasizes that the appointment stage (broadly defined) is the 
primary source of executive and legislative influence over policy outcomes. If agency goals are correctly set up in the first place, then the agency carries out the policies that the executive and legislature would have agreed upon, had they spent the time and effort necessary to do so. Only if there is slippage at the appointment stage do either agency discretion or after-the-fact political control take on any importance. And the better the information at the appointment stage, the smaller the roles of those later steps in determining policy outcomes. On the other hand, if there are any costs to exercising political control (in our model, the loss of $v_{e}$ and $v_{\ell}$ ) then neither latent nor active political control can fully make up for mistakes at the appointment stage.

Our analysis also makes an important point about agency discretion. An agency may set poljcy without direct interference from the legislature or from higher executive authorities. In our scheme, though, this does not constitute agency discretion. Rather, agency discretion occurs when the agency succeeds in choosing a policy in line with agency goals, when those goals differ from what the executive and legislature expected at the appointment stage. Using this definition leads us to assign agency discretion a smaller role in determining policy than would a more naive approach, based solely on the observation of what the agency does and how the elective branches react. This distinction clarifies the conditions under which patterns of policymaking can be changed by restricting agency discretion through improvements in executive and legislative oversight capabilities.

Two kinds of political control figure importantly in our model. Active control occurs when the agent's ideal is far enough out of line with the tolerance of either the executive or the legislature that exercising ex post sanctions becomes worthwhile. Latent control occurs when the agent chooses a policy other than its ideal in order to avoid such sanctions. Depending on the values of the parameters $v_{a}, v_{e}$, and $v_{\ell}$ in our model, the relative sizes of the ranges in which these types of control occur may differ. Ceteris paribus, the better the information available to the elected authorities at appointment time, the less often will active control be exercised. When the agent places a high value on avoiding sanctions (such as the veto), the range for latent oversight is relatively large. Latent oversight is, by definition, never observed; but its role in implementing political control over the agency is in principle just as important as that of active control. Finally, continuous controls, such as budgeting power, may have aspects of both active and latent control. Depending on the agent's choice, a budgetary reaction may be subtle, even unobservable; but the anticipation of a stronger reaction keeps the agent from straying further.

The game among agency decision makers and their elected overseers is complex, and we have captured only certain aspects of this complexity in presenting a general model of bargaining over appointment and policy 
choice. In doing so, we have left aside many other possible sources of political control and agency discretion. These more complicated features of the problem, however, can be fruitfully studied by expanding on our basic model. Though it is unlikely that more "realistic" assumptions will change our general conclusions, the results of such studies of particular institutional features and policy situations would surely prove illuminating.

Our view of the policymaking process has several implications for the conduct of research on policymaking and for the design of reforms of the process. The most basic reflects our design of the model: researchers and reformers should be careful not to fall into the trap of studying the agency in isolation and of seeing as peripheral any executive and legislative actors who do not engage in the day-to-day formulation of policy details. ${ }^{8}$ The analyst of agency policymaking must ask why the agency has the particular structure, procedures, jurisdiction, and personnel that it does; why particular leaders are in office at any given time; and what unspoken expectations agency personnel might have about the conditions under which their elected overseers might invoke sanctions. 9

Such an approach requires the analyst first to identify the relevant actors within the legislative and executive organizations that our model treats as individual players: a particular White House adviser, for example, or the relevant subcommittees in each house of Congress may conduct most of the significant bargaining and oversight regarding a given agency. The next step is to identify their political goals. This is best done through the analysis of previous policy positions and constituency interests, rather than of the often-empty rhetoric of speeches and the preambles of bills.

Finally, the analyst must ascertain the quality and content of the information available to elected officials. The nature of the policy area is one indicator of the kind of uncertainty involved: in a field with rapid technical and tactical innovation, politically desirable policies will be more difficult to forecast than in, say, case-by-case regulation of a stable and wellunderstood market. On the other hand, McCubbins and Schwartz (1984) point out the ease with which policy details and their defects and possible remedies can be reported to legislators by lobbyists for aggrieved interest groups. Aberbach (1987) demonstrates that legislators and their staffs commonly go beyond such "fire-alarm oversight," acquiring extensive information about the arcana of policy decisions within their committee jurisdictions. These findings contrast with the common viewpoint that legislators

\footnotetext{
${ }^{8}$ Compare the studies in the volume edited by Wilson (1980), most of which view such an approach as a virtue.

'Good examples of such an approach are the studies by Cary (1967) and Krasnow, Longley, and Terry (1982).
} 
are generally not sufficiently informed of policy details to perform meaningful oversight. ${ }^{10}$

These same lessons also apply to policy reformers, who often recommend structural or procedural changes in order to change outcomes. A few years ago, this approach led to calls for changes in the commission structure of regulatory agencies, sunset laws, sunshine laws, regulatory budgets, and all manner of other alterations in the organization of agencies and the process of agency decision making and oversight. In many cases the solutions proposed failed to take notice of the real sources of policy and were ineffective or even counterproductive (Noll, 1971; Calvert and Weingast, 1982). For example, sunset provisions for mandatory review and reevaluation of agencies are unlikely to have much effect if legislative control is already exercised through the mechanisms of our model. Moving an agency into or out of a cabinet department is unlikely to have much effect on its policies unless it falls under the jurisdiction of a different congressional committee or comes under altered presidential control (as when the president gains the authority to fire the head of a previously independent agency).

Application of the principles for policy research derived from our theoretical model could thus help policy reformers understand how better to achieve their goals. In some cases policy change is best pursued through structural change in the legislature, such as a change in committee jurisdictions. In other cases only political activity to gain electoral relevance to politicians is likely to bring about change. An inappropriate fixation on the actual locus of decision making, the agency, may lead reformers astray and bring meager or unintended results.

In sum, our model of the policy process clarifies the general relationship between policymaking agencies and the elected representatives who create them. For purposes of policy analysis and reform, it emphasizes the indirect and, in real life, subtle effect of the wishes of elected politicians upon the actions of unelected bureaucrats. It presents a formal definition of agency discretion, distinguishing it from the act of decision making and from the bargains struck among elected officials. These results imply a set of principles that ought to guide students of agency decision processes in assessing the effective source of policy and to demonstrate that policymaking activity is distinct from policy creation.

Finally, our analysis of the structure of the game implicit in the constitutional processes of policymaking offers theoretical insights into the role

${ }^{10}$ As cited in the introductory section. Incidentally, analysts ought not to fall into the trap of supposing that legislators are irrelevant to oversight and information-gathering processes just because most of the work is performed by their staffs. For reasons made clear by Salisbury and Shepsle (1981), both committee and personal staff members in the U.S. Congress act as effective extensions of their bosses. Thus from the standpoint of legislative oversight capabilities, information in the hands of staffers is information in the hands of members. 
of bureaucratic decisions in a democratic system. The process of policymaking that we model, most clearly descriptive of the U.S. federal government, contains a system of checks that constrain the choices of bureaucrats. Under favorable conditions it creates an incentive structure that leads bureaucrats to choose policies reflecting the desires of elected politicians.

Manuscript submitted 4 February 1988

Final manuscript received 22 August 1988

\section{APPENDIX A}

\section{Repeated Game Version of the Basic Model}

Suppose that the basic game is played infinitely many times in succession, with all players learning the outcome of the previous play before proceeding to the next. Future payoffs are discounted by multiplication by a discount factor $\delta$. A player's total payoff for the repeated game is the sum of these discounted payoffs over all plays. This method of repetition is the same as employed by Axelrod (1981).

To keep this relatively brief, we restrict our attention to the case where $x_{a}$ is in the interval $[0,1]$. Also, we require $u_{e}$ and $u_{t}$ to be continuous and single peaked, and $u_{e}(0)$ and $u_{\ell}(1)$ to be nonpositive. We add one additional assumption below.

Define the following values:

$$
\begin{aligned}
& z_{e}=\min \left\{x \mid u_{e}(x) \geq 0\right\} ; \\
& y_{e}=\max \left\{z_{e}, \min \left[x \mid u_{e}[x)>0\right\} ;\right. \\
& \left.z_{\ell}=\max \left\{x\left|u_{\ell}\right| x\right\} \geqslant 0\right\} ; \\
& \left.y_{\ell}=\min \left\{z_{\ell}, \max \left[x\left|u_{e}\right| x\right\} \geqslant 0\right]\right\} .
\end{aligned}
$$

Our final assumption is that $y_{e}<y_{f}$. In words, $y_{e}$ is the smallest value of $x$ such that both the agent and the executive receive nonnegative payoffs, while $y_{t}$ is the largest value such that the agent and the legislature both receive nonnegative payoffs. Due to our previous assumptions, note that $z_{m}, y_{e}, z_{t}$, and $y_{t}$ are always in $[0,1]$, and that $x_{a} \in\left[y_{e}, y_{t}\right]$. Now the following result holds:

Proposmon: Let $x^{*}$ be any point in $\left[y_{e}, y_{\ell}\right]$. Then, for sufficiently large $\delta$, there is a subgame-perfect equilibrium in the repeated game such that, along the equilibrium path, $x^{*}$ is proposed and accepted in every play of the constituent game. For values of $x^{*}$ other than those in $\left[y_{e}, y_{t}\right]$, there is no such equilibrium for any $\delta<1$.

A proof will be furnished by the authors on request.

The equilibria in which the same policy is proposed and accepted on each play are simple and attractive ones. Among those, one in particular stands out as a focal point (Schelling, 1960). The agent's best $x^{*}$ is $x_{a}$. Furthermore, the executive and legislature have just agreed on $x_{a}$ through the appointment process. Since under the assumptions here $x_{d}$ is always available as an equilibrium outcome, it is the one we would expect the players to choose unanimously in playing this noncooperative game.

\section{APPENDIX B \\ Cooperative verwus Nobcooperative Bargaining Models}

We have suggested the Nash bargaining model to describe the result of negotiations between the legislature and the executive, but the use of that cooperative-game model in an ath. 
erwise noncooperative-game context requires some justification. A natural noncooperative model for this procedure would be the following: the executive nominates a candidate, and the legislature may accept or reject that nomination. In case of rejection. the process begins again, with both elected officials losing some utility due to the delay. The unique subgame-perfect equilibrium to such a process is that the executive first nominates an agent with $x_{d}=v_{t}$, and the legislature accepts (proof available on request). In other words, the executive gets its most preferred outcome subject to avoiding a veto by the legislature. One could follow through this reasoning in an obvious manner to derive conclusions similar to those in the text.

However, this bargaining model leaves out an important consideration. Executives and legislatures deal with one another in a series of appointment cases (as well as other matters). Each of these cases is something like the noncooperative bargaining game described above. In general, we could describe this repeated bargaining game as follows. First, the executive nominates a candidate; then the legislature may either accept or reject that candidate. If the legislature accepts, both players receive the corresponding payoff; and if the legislature rejects, both receive zero. Then, whether the nomination was approved or not, the players proceed to the next appointment (to the same or another office). Overall payofis are a discounted sum of the case-by-case payoffs. Of course, the game could be complicated by varying the payoffs from one office to the next, but as long as the players have common expectations about those future stakes, this would make no important difference in their overall behavior.

Set up in this way, the repeated nomination process is a garden-variety repeated game with discounting. As such, it is subject to the Folk Theorem (see Fudenberg and Maskin, 1986): any combination of average payoffs that gives each player more than its minimax payoff can be sustained as a subgame-perfect equilibrium in the repeated game, provided that the discounting is not too heavy. This means that any series of appointments of agents, each of whose ideal points lies inside the range $\left[1-v_{e}, v_{t}\right]$, could occur in equilibrium, given the appropriate pattern of expectations and retaliation by the players (proof available upon request).

Although we have no noncooperative-game criterion for deciding which of the infinity of equilibria the players in this appointment game might settle on, intuition tells us that the results are likely to be appointments somewhere in the "middle" of the no-veto interval. One appealing objective criterion for identifying such points is the Nash bargaining solution (NBS) (Nash, 1950). Here we take the view that the axions defining the NBS are criteria for a good prediction technique for bargaining outcomes, rather than criteria for a "fair arbitration scheme," as they are sometimes presented (e.g., Luce and Raiffa, 1957). For present purposes the particular choice of a bargaining prediction method is inconsequential provided that it is centrally located and responds to the relative bargaining positions of the players.

\section{REFERENCES}

Aberbach, Joel. 1987. The congressional committee intelligence system. Congress and the presidency, 14:51-76.

Altison, Graham T. 1971. The essence of decision. Boston: Little, Brown.

Arnold, R. Douglas. 1979. Congress and the bureaucracy. New Haven: Yale University Press. Axelrod, Robert. 1981. The emergence of cooperation among egoists. American Political Science Review, 75:306-18.

Calvert, Randall L., Mark J. Moran, and Barry R. Weingast. 1988. Congressional intuence over policymaking: The case of the FTC. In Mathew McCubbins and Terry Sullivan, eds., Congress: Structure and Policy. Cambridge: Cambridge University Press. 
Calvert, Randall L., and Barry R. Weingast. 1982. Runaway bureaucracy and congressional oversight: Why reforms fail. Policy Studies Review, 1:557-64.

Cary, William. 1967. Politics and the regulatory commission. New York: McGraw-Hill.

Clarkson, Kenneth W. 1981. Legislative constraints. In Kenneth W. Clarkson and Timothy J. Muris, eds., The Federal Trade Commission since 1970. Cambridge: Cambridge University Press.

Dodd, Lawrence, and Richard Schott. 1979. Congress and the administrative state. New York: Wiley.

Fenno. Richard F., Jr. 1978. Home style: Congressmen in their constintencies. Boston: Little, Brown.

Fiorina, Morris P. 1981. Congress: A mismatch of incentives and capabilities. In Lawrence C. Dodd and Brace I. Oppenheimer, eds., Congress reconsidered. 2nd ed. Washington, DC: Congressiona! Quarterly Press.

Fudenberg, Drew, and Eric Maskin. 1986. The folk theorem in repeated games with discounting and with incomplete information. Econometrica, 54:533-54.

Hamilton, Alexander, John Jay, and James Madison. 1966. The Federalist papers, selected and edited by Roy P. Fairfield. 2nd ed. Garden City, NY: Doubleday. (Original work published in 1788.)

Hammond, Thomas H., Jeffrey S. Hill, and Gary J. Miller. 1986. Presidents, Congress, and the "congressional control of administration" hypothesis. Presented at the annual meeting of the American Political Science Association, Washington, DC.

Hill, Jefirey S. 1985. Why so much stability? The role of agency determined stability. Public Choice, 46:275-87.

Katzmann, Robert A. 1980. Regulatory bureaucracy: The Federal Trade Commission and antitust policy. Cambridge: MIT Press.

Krasnow, Erwin G., Lawrence D. Longley, and Herbert A. Terry. 1982. The politics of broadcast regulation. New York: St. Martin's Press.

Luce, R. Duncan, and Howard Raiffa. 1957. Games and decisions. New York: Wiley.

Mayhew, David R. 1974. Congress: The electoral connection. New Haven: Yale University Press.

McCubbins, Mathew D. 1985. The legislative design of regulatory structure. American Joumal of Political Science, 29:721-48.

McCubbins, Mathew D., Roger G. Noll, and Barry R. Weingast. 1987. Administrative procedures as instruments of political control. Joumal of Law, Economics, and Organization, 3:243-77.

McCubbins. Mathew D., and Thomas Schwartz. 1984. Congressional oversight overlooked: Police patrols vs. fire alarms. American Joumal of Political Science, 28:165-79.

Moe, Terry. 1985. Control and feedback in economic regulation. American Political Science Review, 79:1094-1116.

Nash, John F. 1950. The bargaining problem. Econometrica, 18:155-62.

Neustadt, Richard E. 1980. Presidential power, 2nd ed. New York: Wiley.

Niskanen, William. 1971. Bureaucrocy and representative government. Chicago: Aldine.

Noll, Roger. 1971. Reforming regulation. Washington, DC: Brookings Institution.

Ogul, Morris S. 1981. Congressional oversight: Structures and incentives. In Lawrence C. Dodd and Bruce 1. Oppenheimer, eds., Congress reconsidered. 2nd ed. Washington, DC: Congressional Quarterly Press.

Rubinstein, Ariel. 1982. Perfect equilibrium in a bargaining model. Econometrica, 50:97-109.

Salisbury, Robert H., and Kenneth A. Shepsle. 1981. Congressional staff turnover and the tiesthat-bind. American Political Science Review, 75:381-96.

Schelling, Thomas C. 1960. The strategy of confict. Cambridge: Harvard University Press. 
Scher, Seymour. 1963. Conditions for legislative control. Joumal of Politics, 25:526-51.

Weingast, Barry R. 1984. The congressional-bureaucratic system: A principal-agent perspective (with applications to the SEC). Public Choice, 44:147-91.

Wilson, James Q., ed. 1980. The politics of regulation. New York: Basic Books. 